\title{
The lithospheric-scale deformation in NE Tibet from joint inversion of receiver function and surface wave dispersion
}

\author{
Yangfan Deng ${ }^{1,2, *}$, Jiangtao $\mathrm{Li}^{2}$, Xiaodong Song ${ }^{2,3}$, Hongyi $\mathrm{Li}^{2,4}$, and Tao $\mathrm{Xu}^{5}$ \\ ${ }^{1}$ State Key Laboratory of Isotope Geochemistry, Guangzhou Institute of Geochemistry, Chinese Academy of Sciences, Guangzhou, \\ China \\ ${ }^{2}$ Department of Geology, University of Illinois at Urbana-Champaign, Champaign, IL, USA \\ ${ }^{3}$ School of Geodesy and Geomatics, Wuhan University, Wuhan, China \\ ${ }^{4}$ School of Geophysics and Information Technology, China University of Geosciences, Beijing, China \\ ${ }^{5}$ State Key Laboratory of Lithosphere Evolution, Institute of Geology and Geophysics, Chinese Academy of Sciences, Beijing, \\ China
}

\section{Article history:}

Received 18 January 2018

Revised 20 December 2018

Accepted 18 January 2019

Keywords:

Non-linear inversion, Positive correlation, Heterogeneous Moho, Coupled deformation, Asian lithosphere

\section{Citation:}

Deng, Y., J. Li, X. Song, H. Li, and T. Xu, 2019: The lithospheric-scale deformation in NE Tibet from joint inversion of receiver function and surface wave dispersion. Terr. Atmos. Ocean. Sci.,30, 127-137, doi: 10.3319/ TAO.2019.01.18.03

\begin{abstract}
As a region far away from the Indian-Asian collision front, Northeastern (NE) Tibet has attracted great attention due to its implications for the plateau growth and the devastating earthquakes. Several geodynamic models have been proposed for the deformation mechanism of NE Tibet, but it remains controversial. Here we introduce the crustal $\mathrm{Vp} / \mathrm{Vs}$ ratios from the H-k stacking to the joint inversion of receiver function and surface wave dispersion, which is based on the Neighborhood Algorithm. The crustal and uppermost mantle velocities are obtained beneath 203 stations in NE Tibet. The results show (1) deep Moho in Songpan-Ganzi and Qiangtang terranes, and distinct Moho depth between northwest and southeast Qilian; (2) positive correlation between the average velocity in the crust and in the uppermost mantle, suggesting a coupled lithospheric-scale deformation; (3) diverse high upper mantle velocities distributing in northern part of the study region, which may indicate the existing of local lithosphere or a non-uniform southward subduction of Asian lithosphere.
\end{abstract}

\section{INTRODUCTION}

Several geodynamic models have been proposed to explain the uplift and outgrowth of the Tibetan Plateau (TP), such as rigid block model, continuum model, and crustal flow model. Block model suggests that lithospheric-scale faults exhibit as boundaries separating the continent interior into a limited number of tectonic blocks, and the deformation takes place mainly along the strike-slip faults (Tapponnier et al. 2001). Continuum model allows stress to transfer within and across blocks and the deformation is broadly distributed (e.g., Neil and Houseman 1997; Zhang et al. 2004). In addition, the crustal flow model, in which the mid-lower crust of the plateau interior moves eastward and is diverted to the northeast and southeast around the Sichuan basin, is

\footnotetext{
* Corresponding author

E-mail: yangfandeng@gig.ac.cn
}

commonly used to explain the topography gradient around the TP (Royden et al. 1997; Clark and Royden 2000).

Due to its location and devastating earthquakes, Northeastern (NE) Tibet has long been an ideal site to study the deformation and uplift of the TP. Widespread mid-crustal low-velocity zones (LVZs) (Bao et al. 2013; Li et al. 2014) and low resistivity zones (Le Pape et al. 2012) were observed in the Songpan-Ganzi terrane (SGT) that penetrate across Kunlun fault (KF), consistent with the crustal flow model. However, isolated LVZs were observed under Qilian from ambient noise (Bao et al. 2013; Li et al. 2014), deep seismic sounding (Zhang et al. 2011, 2013), and deep seismic reflection results (Gao et al. 2013; Guo et al. 2015), which favor continuous shortening as a deformation mechanism. Furthermore, observed Moho offsets (Zhu and Helmberger 1998; Vergne et al. 2002; Zhang et al. 2011; Ye et al. 
2015) and the correlation between GPS and SKS splitting (Wang et al. 2008; León Soto et al. 2012; Chang et al. 2017) support a coupled lithospheric scale deformation (Tapponnier et al. 2001; Yin et al. 2008; Ye et al. 2015). The images from joint inversion of receiver function (RF) and surface wave dispersion argued that the rigid block model and crustal flow model could be concomitant (Liu et al. 2014). In summary, though abundant geophysical investigations have been conducted in this region, the deformation mechanism in this region is still controversial, which is the key to understand the uplift and growth of the TP.

Since more geophysical data have become available, joint inversions have been commonly used to resolve the ambiguities inherent in using individual methods separately. A common method is the joint inversion of surface wave dispersions and RFs (Julià et al. 2000). However, the traditional joint inversion usually sets the crustal $\mathrm{Vp} / \mathrm{Vs}$ to the global average of 1.75 , which would bias the crustal structure ( $\mathrm{Li}$ et al. 2017a). Moreover, the results from the traditional linear inversion may also be affected by the starting model. In order to better illuminate the lithospheric structure in NE Tibet, here we utilize the data recorded by 230 stations and apply the nonlinear joint inversion of RFs and surface wave dispersions with independently constrained $\mathrm{Vp} / \mathrm{Vs}$ ratios (from H-kappa stacking). The approach allows us to resolve lithospheric $\mathrm{S}$ velocity, surface sedimentary layers, and Moho depth. Our results suggest a coupled lithospheric-scale deformation in NE Tibet, which could provide a possible common process of the plateau growth.

\section{DATA}

Because we introduce the specific crustal Vp/Vs on the joint inversion of RF, surface wave dispersion, so the data used in this study include three types, i.e., RFs, dispersion curves of surface wave group and phase velocities, and $\mathrm{Vp} /$ Vs ratio from H-k stacking.

The RF data came from 230 broadband stations archived from 2007 - 2011, including 90 stations from Incorporated Research Institutions for Seismology (IRIS), 118 stations from China Earthquake Administration (CEA) recorded during 2007 - 2009 (Data Management Centre of China National Seismic Network 2007; Shen et al. 2008; Zheng et al.2010), and 22 stations from Institute of Geology and Geophysics, Chinese Academy of Sciences (IGGCAS) recorded between November 2010 and June 2011 (Xu et al. 2014; Wu et al. 2015) (Fig. 1). To calculate the RFs, we selected teleseismic $\mathrm{P}$ waveforms from earthquakes with magnitude $\mathrm{Mw} \geq 5.5$ and epicentral distance range from 30 $-90^{\circ}$. Before using the time-domain iterative deconvolution method (Ligorría and Ammon 1999) to obtain the RFs, we applied the bandpass filter of $0.1 \sim 1.0 \mathrm{~Hz}$ to the raw data and Gaussian filter with a width of 2.5 to reduce high-frequency noise. Afterwards, we performed a quality control process based on the fitting ratio, amplitude, and harmonic stripping (Shen et al. 2013; Deng et al. 2015) on the RFs of

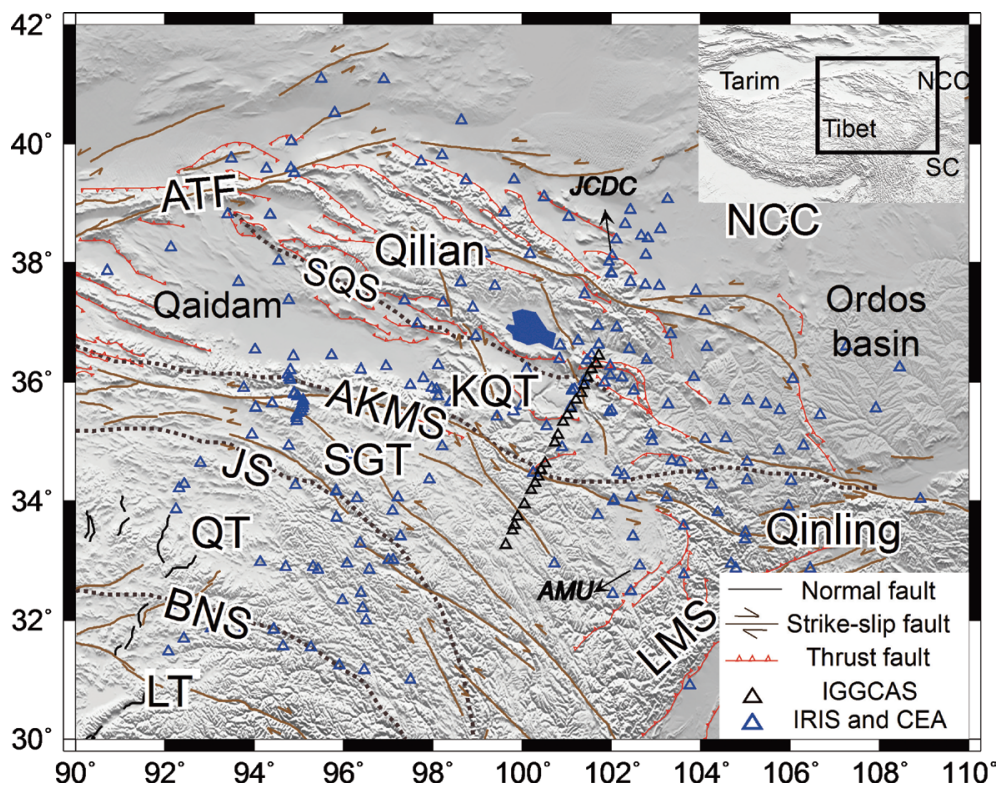

Fig. 1. Seismic stations (triangles) used in this study with surface topography and geological elements. Blue triangles represent regional stations operated by the China Earthquake Administration (CEA) and Incorporated Research Institutions for Seismology (IRIS); black triangles are stations deployed by the Institute of geology and Geophysics, Chinese Academy of Sciences (IGGCAS). Stations JCDC and AMU are marked for Fig. 4. ATF, Altyn Tagh fault; BNS, Bangong-Nujiang suture; JS, Jinsha suture; AKMS, Animaqing-Kunlun-Muztagh suture; SQS, South Qilian suture; KF, Kunlun fault; LMS, Longmenshan fault. The geological terranes are: LT, Lhasa terrane; QT, Qiangtang terrane; SGT, Songpan-Ganzi terrane; KQT, Kunlun-Qaidam terrane; NCC, North China Craton. 
all the stations ( 23000). Finally, we obtained 8354 good observed RFs over 203 stations.

The dispersion data were extracted from the recent surface wave tomography of China (Bao et al. 2015), who used both ambient noise and earthquake data beneath more than 1300 stations, including 864 CEA permanent stations from 2008 - 2011, 401 temporary PASCCAL stations, and 51 permanent stations from the IRIS Data Management Center. More than 700000 dispersion curves were measured to generate group and phase velocity maps at periods of $10-70 \mathrm{~s}$ (group velocity maps extend to $140 \mathrm{~s}$ ). In this study, according to the inverse-weighted distance algorithm, we extracted group and phase velocity dispersion curves at each of our stations from the dispersion maps of $10-70 \mathrm{~s}$, which are better constrained with both the ambient noise and earthquake data.

$80 \%$ of $\mathrm{Vp} / \mathrm{Vs}$ data in this study were from Zheng et al. (2016), who used 847 teleseismic earthquakes and obtained $\mathrm{Vp} / \mathrm{Vs}$ ratios beneath 143 stations by using the H-k stacking method. In addition, for IGGCAS stations, we used the $\mathrm{Vp} / \mathrm{Vs}$ ratios from $\mathrm{Xu}$ et al. (2014). For the remaining stations, we obtained the $\mathrm{Vp} / \mathrm{Vs}$ ratios by applying the H-k stacking method (Zhu and Kanamori 2000). Two examples of the estimation are shown in Figs. $2 b$ and c. Although the measurements have uncertainties, they generally have a consistent pattern among stations (Fig. 2), which shows the relatively higher Vp/Vs in Lhasa terrane (LT), Qiangtang terrane (QT), and SGT, but lower in Qilian.

\section{METHOD}

The teleseismic $\mathrm{P}$-wave RF is sensitive to shear velocity contrast and depth-velocity product, instead of velocity alone, while the surface wave dispersion is sensitive to vertical shear-velocity averages but insensitive to velocity discontinuities. Thus, joint inversion of RF and surface wave dispersion has been widely used to reduce parameter ambiguity in the inversion (Julià et al. 2000). However, the joint inversion is greatly influenced by the $\mathrm{Vp} / \mathrm{Vs}$ ratio in the crust, which is often unconstrained and normally set to the global average (1.75). The wrong $\mathrm{Vp} / \mathrm{Vs}$ ratio would bias the crustal structure (Li et al. 2017a).

Here, we use the crustal Vp/Vs ratio beneath every station obtained from H-k stacking and perform the joint inversion of receiver function and dispersion, which is based on the fast global search method, the Neighborhood Algorithm (Sambridge 1999; Xu et al. 2013; Li et al. 2017a). The model parameterization is similar as Li et al. (2017a). The crust and the mantle are parameterized as cubic splines, with fixed numbers of nodes of 12 and 9 , respectively. The depth

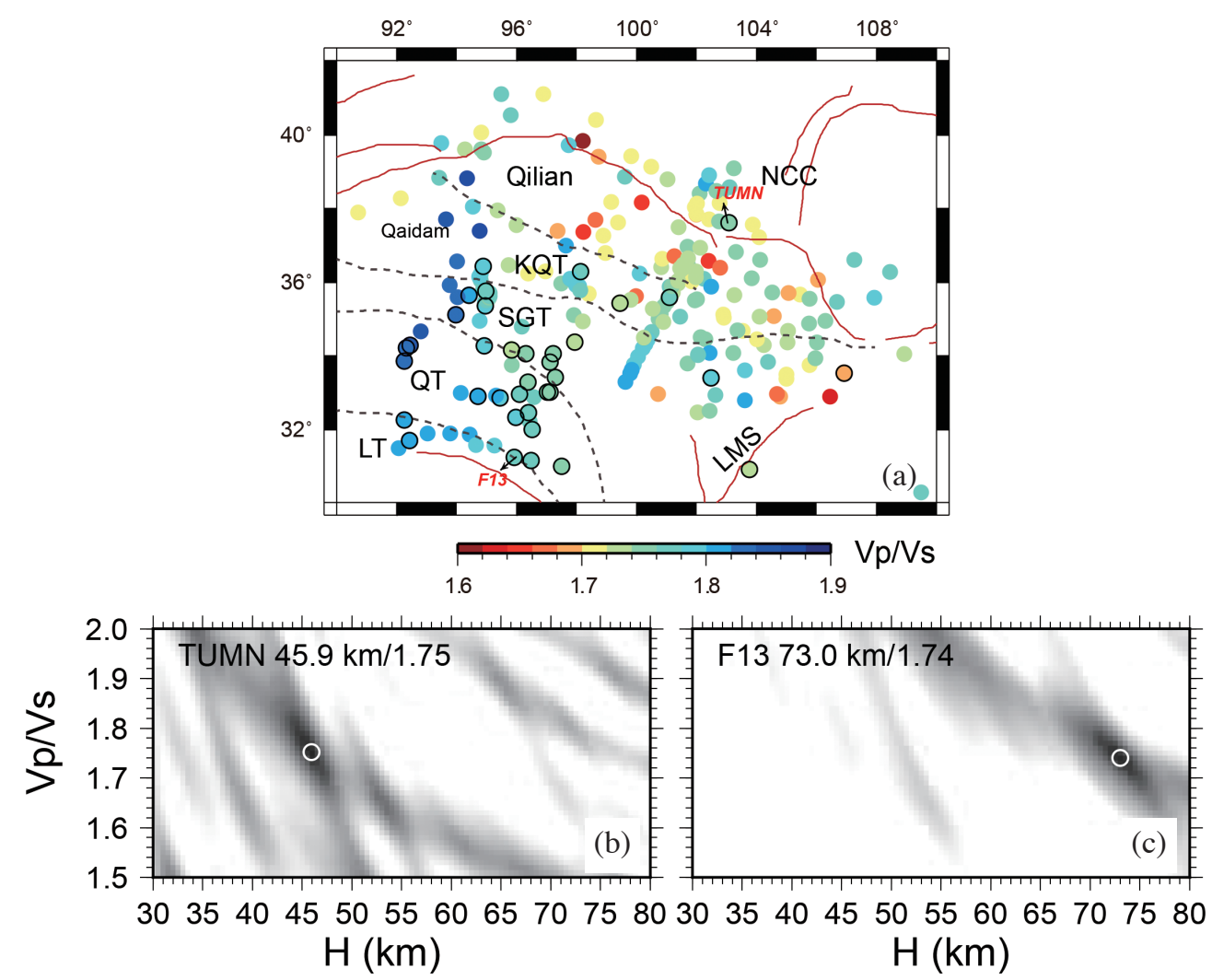

Fig. 2. The Vp/Vs ratio used in this study. The tectonic units are the same as Fig. 1. The circles with black border indicate the results from the H-k stacking method in this study. Others refer to Xu et al. (2014) and Zheng et al. (2016). Two stations for (b) and (c) are labeled by red characters in (a). The average crustal $\mathrm{Vp} / \mathrm{Vs}$ ratio and Moho depth of the two stations are marked with white circles in (b) and (c). 
of the last (bottom) node in the mantle is fixed at $150 \mathrm{~km}$. Specifically, we introduced a separate sedimentary layer at the surface, which has a great influence on the waveform of the RF, particularly the beginning portion. We used a linear gradient for the sedimentary layer, but allowed the thickness to vary. We fixed the $\mathrm{Vp} / \mathrm{Vs}$ ratio for the sedimentary layer at 2.0 as it trades off with the sedimentary layer thickness (not of interest in this study), the $\mathrm{Vp} / \mathrm{Vs}$ ratio for the rest of the crust beneath the station from $\mathrm{H}-\mathrm{k}$ stacking, and the ratio for the mantle at the global average of 1.795. The velocities below $95 \mathrm{~km}$ from Bao et al. (2015) are also used as reference in the joint inversion, where the resolution of dispersion curves degrades. The surface wave inversion alone is applied first to get the initial model for the joint inversion, and 200200 total models are searched to get the final best fitting model.

Li et al. (2017a) has done several synthetic tests to illustrate the robustness of this method. Here we perform two synthetic tests to emphasize that the joint inversion could recover the correlated or anti-correlated velocity structure between crust and mantle (Fig. 3). For test 1, the input model has $2 \mathrm{~km}$ sediment, three layers in the crust, which includes a low velocity zone in the middle crust over a half-space of low velocity in the mantle. For test 2 , the input model is the same as test 1 in the crust, but has high velocity in the mantle. Even though the surface wave inversion could recover the dispersion data (group and phase), the recovered velocity model is smoother than the input model. However, the joint inversion can recover well both input models, including the input Vs values and discontinuities. The predicted $\mathrm{RF}$ and dispersion curves for the inverted final model also agree well with the input ("observed") data. These results suggest that the correlation between crustal and uppermost mantle Vs observed in our data is robust, rather than biased from the trade-off between crustal and mantle structures.

\section{RESULTS}

\subsection{Joint Inversion Using Real Data}

Two examples using real data (for station JCDC and AMU) are shown in Fig. 4. Obviously, the Vs model from joint inversion reveals more detailed features in the crust and has higher resolution in the mantle, compared with the Vs model from surface wave inversion alone. Note the inclusion of the sedimentary layer improves the fit to the direct $\mathrm{P}$ arrival near zero time in the RF, in comparison with the previous study (Xu et al. 2013). Because of the depth trade-off in surface wave dispersion, the improved resolution for the crust will also improve the resolution for the mantle, which is mostly constrained by the dispersion data and the background reference model. That is another advantage of this study compared with that from Zheng et al. (2016). Specifically, the Moho depth beneath JCDC is $\sim 46 \mathrm{~km}$, and there is a distinct high velocity layer in the crust. Comparatively, the Moho depth beneath AMU is $\sim 45 \mathrm{~km}$, and the velocity is smooth in the crust but high in the uppermost mantle.

\subsection{Velocity Maps at Different Depths}

The sedimentary layer has strong effect on the RFs and may bias the final results. The inclusion of searching the thickness and velocities of this layer not only make this method able to recover well the real sedimentary layer, but also prevent its contamination on the robustness of the crustal LVZ distribution and deep crustal structure ( $\mathrm{Li}$ et al. 2017a). The velocity map at $2 \mathrm{~km}$ shows distinct low velocity beneath basins, such as the Qaidam basin, Gonghe basin, and Ordos basin (Fig. 5a). These features highlight the effectiveness of introducing sedimentary layer in the inversion.

The velocity map at $20 \mathrm{~km}$ (Fig. 5b) shows the uppermiddle crustal characteristics. SGT and QT are typified by low velocities, which may have penetrated across the KF. This result is consistent with previous studies (Le Pape et al. 2012; Jiang et al. 2014; Li et al. 2014, 2017b). We can also find isolated low velocity in northwestern Qilian, which is considered as the initial stage of deformation (Bao et al. 2013).

The velocity map at $60 \mathrm{~km}$ (Fig. 5c) indicates Moho depth variation. In general, the lower velocity indicates a deeper Moho. For example, SGT, QT, and LT terranes present low velocity at this depth, which is consistent with the deeper Moho. The same feature could also be observed in the northwestern Qilian. The Qaidam basin has a shallower Moho, sandwiched between Qilian and SGT.

The velocity at $80 \mathrm{~km}$ (Fig. 5d) illustrates the property of uppermost mantle. Most of the SGT and QT exhibit low velocity, which reveals a close correlation between the thick (> $60 \mathrm{~km}$ ) crust and the presence of an upper-mantle lowvelocity zone beneath the QT and SGT.

\subsection{Moho Depth}

With the inclusion of constrained $\mathrm{Vp} / \mathrm{Vs}$ in the joint inversion, the Moho depth is more robust than the traditional joint inversion ( $\mathrm{Li}$ et al. 2017a). The deepest Moho $(\sim 75 \mathrm{~km})$ in this study area is observed beneath QT (Fig. 6a). The Moho lies at the depth of $60-70 \mathrm{~km}$ in the SGT. In the Qaidam basin, however, the Moho becomes shallower to $\sim 50-55 \mathrm{~km}$ depth. The NW Qilian has a relatively deeper Moho ( $\sim 55$ - $65 \mathrm{~km}$ depth) than that of the SE Qilian, Ordos basin and West Qinling ( 40 - $55 \mathrm{~km}$ depth). Compared with the Moho depth from H-k stacking (Xu et al. 2014; Zheng et al. 2016), our Moho depth is more robust because the multiple phases are not generally clear and the sediment would also bias the Moho depth (Yeck et al. 2013).

Figure $6 \mathrm{~b}$ presents the standard deviation of the 20000 models that have smaller misfits with the observations in our search-based inversion scheme. The standard deviation 
(a) S velocity $(\mathrm{km} / \mathrm{s})$


(b) S velocity $(\mathrm{km} / \mathrm{s})$

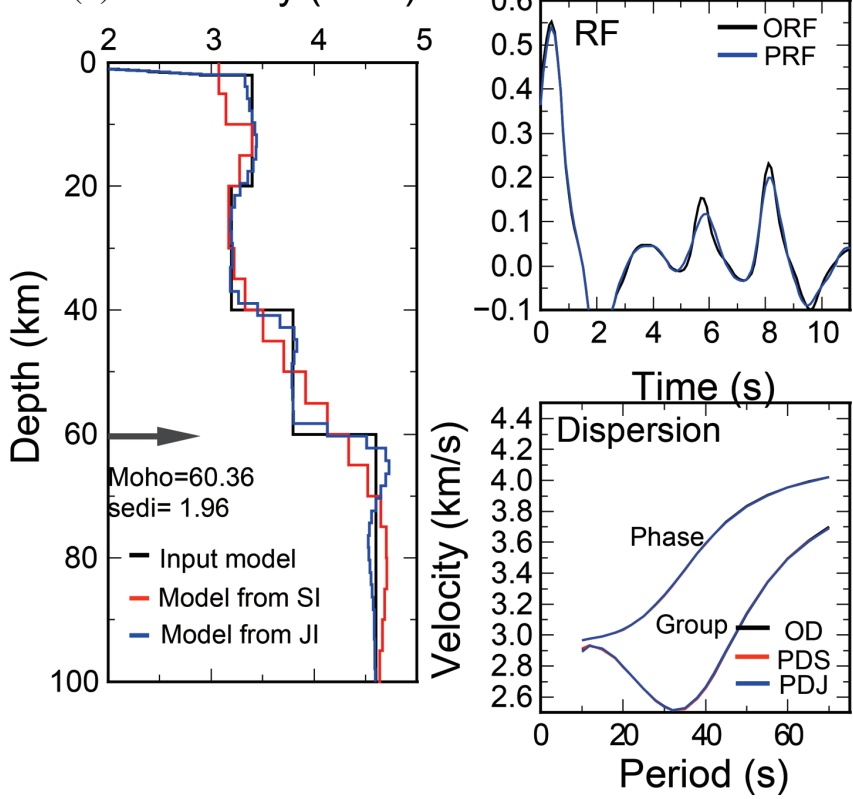

Fig. 3. The synthetic tests of the joint inversion of RF and dispersion with specified Vp/Vs (1.75 in the crust). (a) The input model has a 2-km sedimentary layer, three layers in the crust (18 km upper crust, $20 \mathrm{~km}$ middle crust, and $20 \mathrm{~km}$ lower crust) and one layer in the mantle. (b) The input model is the same as (a) except the high velocity in the mantle. The left panel: the best fitting model of the joint inversion (JI) (blue) and the best fitting model of the surface wave inversion alone (SI) (red). The arrow marks the Moho depth from the JI. The right topo panel: the observed RF (ORF, black envelope) and the predicated (calculated) RF from the best-fitting model of the JI (PRF) (blue); the right bottom panel: the observed Rayleigh wave phase and group dispersion (OD) curves (black), the predicated Rayleigh wave phase and group dispersion (PDJ) curves from the JI (blue), and the predicated Rayleigh wave phase and group dispersion (PDS) curves from the SI (red). The inverted sedimentary and crustal thicknesses from joint inversion are similar with the input model, as well the velocity value.

(a) S velocity $(\mathrm{km} / \mathrm{s})$

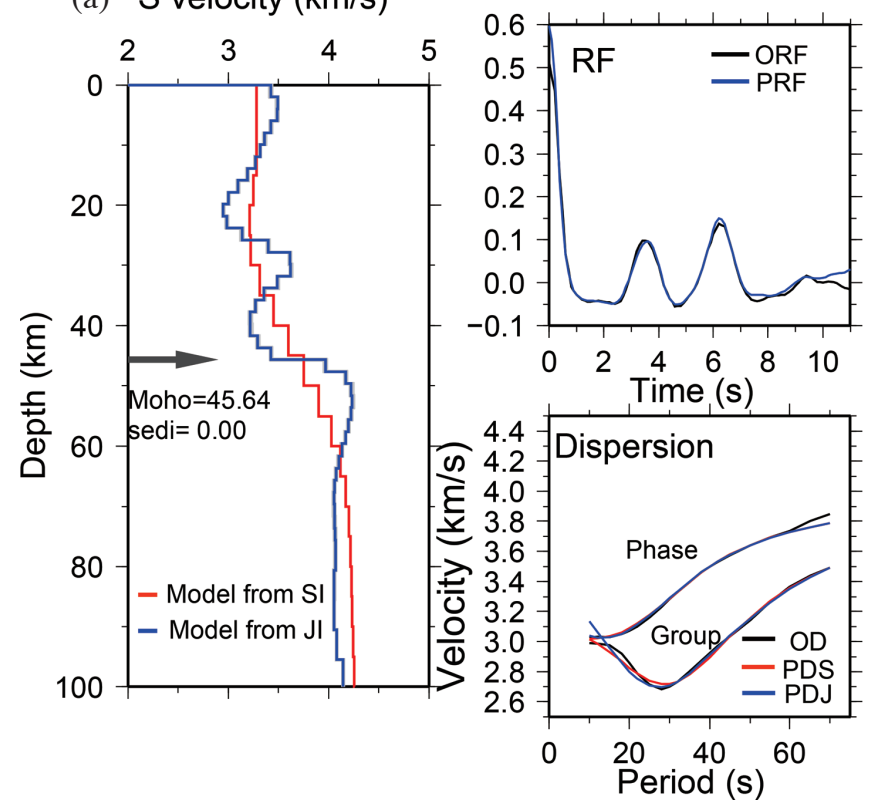

(b) S velocity $(\mathrm{km} / \mathrm{s})$

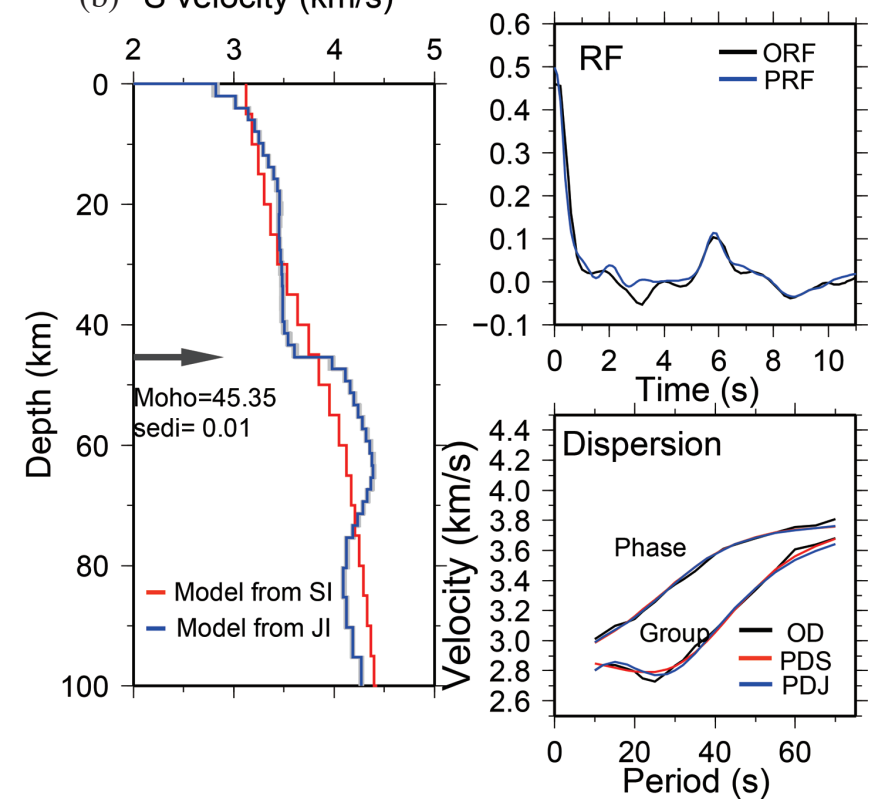

Fig. 4. Two examples of joint inversion of RF, dispersion with specified Vp/Vs using real data. (a) The example is for station JCDC. (b) The example is for station AMU. The locations of the two stations are marked in Fig. 1. The abbreviations are the same as Fig. 3. The velocity model from JI could fit well with the observed RF and dispersion. 

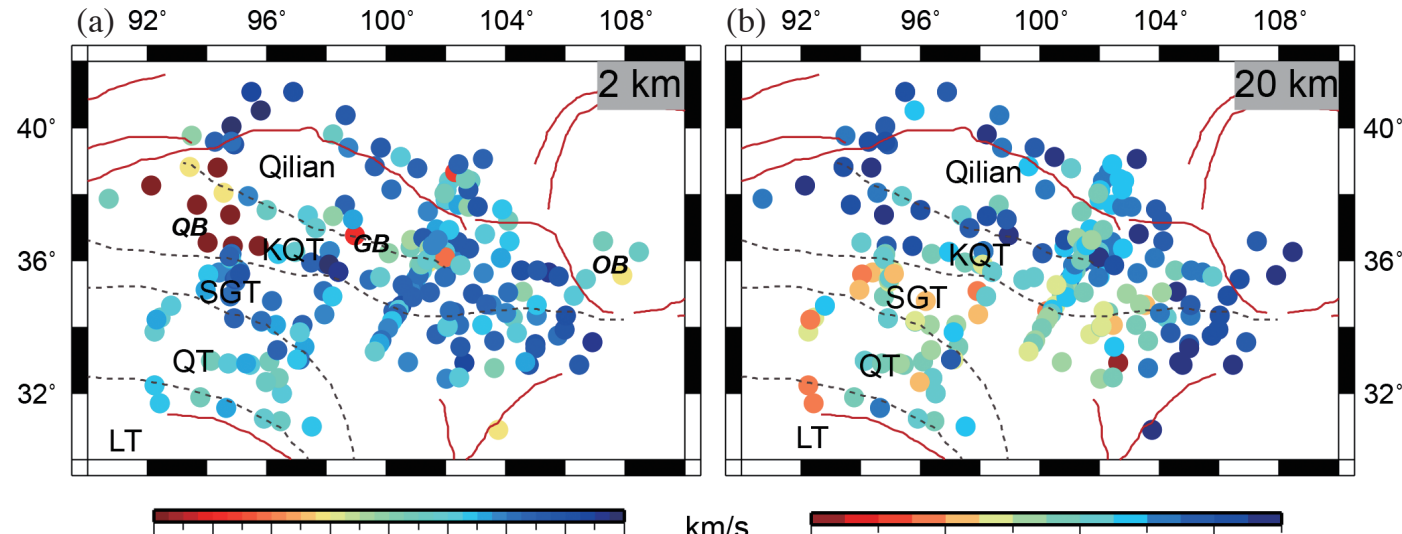

$\mathrm{km} / \mathrm{s}$
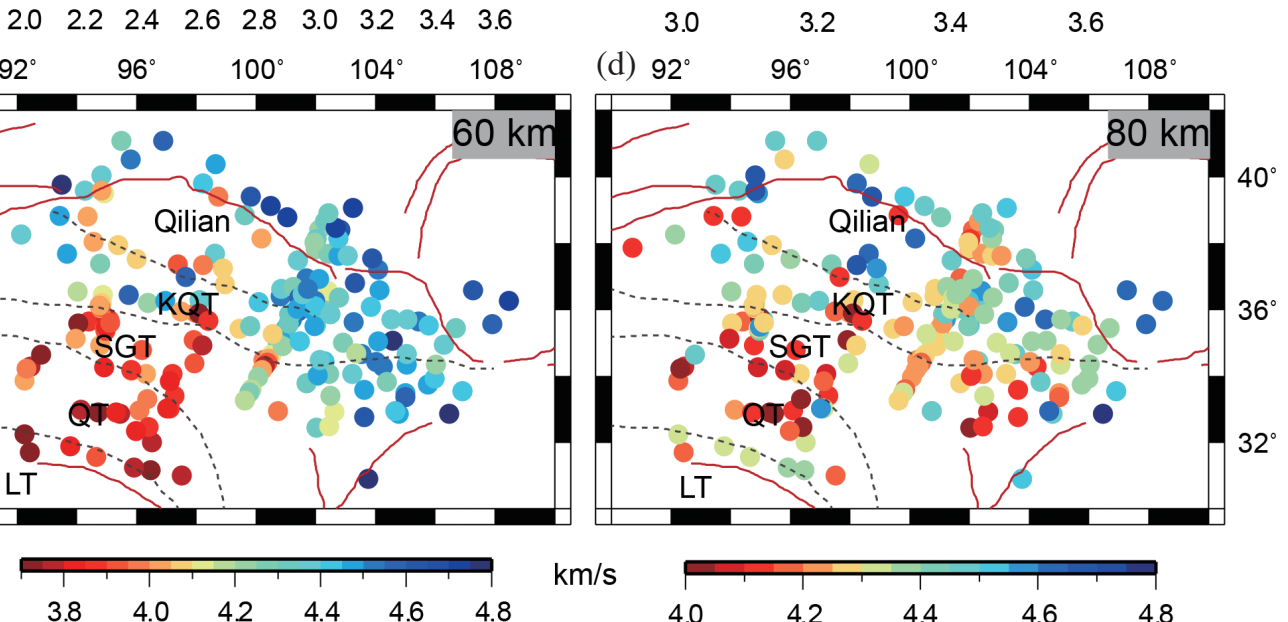

Fig. 5. Inverted shear wave velocity at 2, 20,60, and $80 \mathrm{~km}$. The tectonic units are the same as Fig. 1. QB: Qaidam basin; GB: Gonghe basin; OB: Ordos basin.



(d) $92^{\circ} \quad 96^{\circ} \quad 100^{\circ} \quad 104^{\circ} \quad 108^{\circ}$ 
is quite small compared to the Moho variations, indicating that our inversion results are robust.

\section{DISCUSSION}

\subsection{Does the Asian Lithosphere Subduct Beneath NE TP?}

It is well accepted that the Indian lithosphere has subducted beneath southern TP, even though the frontier is still debated. However, whether the Asian lithosphere has subducted beneath TP remains controversial. Meyer et al. (1998) suggested the south-directed subduction in the NE Tibet based on surface geology and geomorphology. Tapponnier et al. (2001) proposed a model of oblique southward lithosphere subducting beneath NE TP. Regional seismic-reflection profiles and strata data (Yin et al. 2008), as well as receiver function studies of local temporary seismic arrays have reported evidence for possible southward subducting of Asian lithosphere beneath central and northern Tibet (Kind et al. 2002; Zhao et al. 2010, 2011; Ye et al. 2015). However, a seismic tomography study (Liang et al. 2012) observed a low velocity upper mantle beneath northern Tibet, which argues against subducting of the Asian lithosphere. Wei et al. (2017) used the Rayleigh wave tomography and further proposed a limited southward underthrusting of the Asian lithosphere. Furthermore, the recent S-RF images are inconsistent with the model of Asian mantle lithosphere subducting beneath the Tibet Plateau (Shen et al. 2015).

In order to better illustrate the velocity structures at different terranes, we slice four profiles from SW to NE cutting across the region. Profile (a) spans from the boundary between LT and QT to the North China Craton (NCC). The Moho depth decreases gradually from $\sim 70 \mathrm{~km}$ in QT to $\sim 65 \mathrm{~km}$ in SGT, to $\sim 60 \mathrm{~km}$ in Kunlun-Qaidam terrane (KQT), and then increases to $\sim 65 \mathrm{~km}$ in Qilian and finally decreases to $\sim 50 \mathrm{~km}$ in NCC. Prominent low velocities are present in QT and SGT, and have penetrated across the KF. Qilian also has low velocity in the middle crust. Profile (b) extends from KQT to the NCC. The Moho is deeper in Qilian, but shallower in KQT and NCC. A low velocity zone is also present in the middle crust of Qilian. The profiles (c) and (d) have relatively flat Moho. The low velocities still exist in the crust beneath SGT and KQT along Profile (c), but not Qilian. Nevertheless, there is no apparent low velocity existing along profile (d). In the northern part of these four slices, the uppermost mantle exhibits high velocity. However, the high velocities in profiles (a) and (b) of the upper mantle do not connect with the southern part.

In summary, the velocity structure is heterogeneous in different tectonic units in this region. Even though the connected high velocity of the upper mantle in the northern part of profiles (c) and (d) seems to suggest a southward subduction of the Asian lithosphere, we do not see this fea- ture in profiles (a) and (b). Here we propose two alternative explanations. First, the Asian lithosphere does subduct beneath TP, but the subduction is not uniform. Second, there is no Asian southward subduction, and the high velocity just reflects the variation of local lithospheric structure. The heterogeneity may explain the different models proposed in the previous studies (discussed above).

\subsection{The Coupled Deformation in NE Tibet}

Moho offsets across major faults are widely reported in this region (Zhu and Helmberger 1998; Vergne et al. 2002; Zhang et al.2011; Tian et al.2014; Ye et al.2015; Deng et al. 2018). The correlation between GPS measurements, crustal anisotropy and the mantle deformation field measured by shear-wave splitting suggests that the deformation of lithosphere is vertically coherent (Wang et al. 2008, 2016; Chang et al. 2017). Azimuthal anisotropy derived from multimode Rayleigh wave tomography implied coupled deformation throughout the whole lithosphere (Pandey et al. 2015).

From Fig. 7, we have found another interesting feature that the low velocity in the crust corresponds to the low velocity in the mantle. In order to better confirm this hypothesis, we calculate the average velocity in the crust (from $4 \mathrm{~km}$ below sediment to Moho) and uppermost mantle (top $20 \mathrm{~km}$ ). Figure 8 shows the distribution of crustal and uppermost mantle velocities and there was a significantly positive correlation between them. In other words, the stronger crust corresponds to the stronger mantle, which is consistent with the coupled lithospheric-scale deformation in this region (Deng et al. 2018; Xu et al. 2018). It should be noted that, the $\mathrm{Vp} / \mathrm{V}$ s have uncertainties from the H-k stacking method, while the different $\mathrm{Vp} / \mathrm{Vs}$ would mainly have trade-off with the Moho depth but not the velocity (Li et al. 2017a; Deng et al. 2018), which herein does not change our final conclusion.

\section{CONCLUSION}

In an effort to understand the deformation in NE Tibet, we perform a nonlinear joint inversion of receiver function and surface wave dispersion with specified $\mathrm{Vp} / \mathrm{Vs}$ beneath 230 stations. The crustal and uppermost mantle velocities are obtained beneath the 203 stations. The main conclusions from the detailed velocity structure include: (1) The crustal thickness is heterogeneous in different tectonic units. (2) Positive correlation exists between crustal velocity and uppermost mantle velocity, which suggests a coupled lithospheric-scale deformation in this region. (3) Two alternative explanations are proposed for the diverse high velocities in the upper mantle distributing in northern part of the region, which may indicate a non-uniform southward subduction of the Asian lithosphere or just reflect local lithosphere variations. 

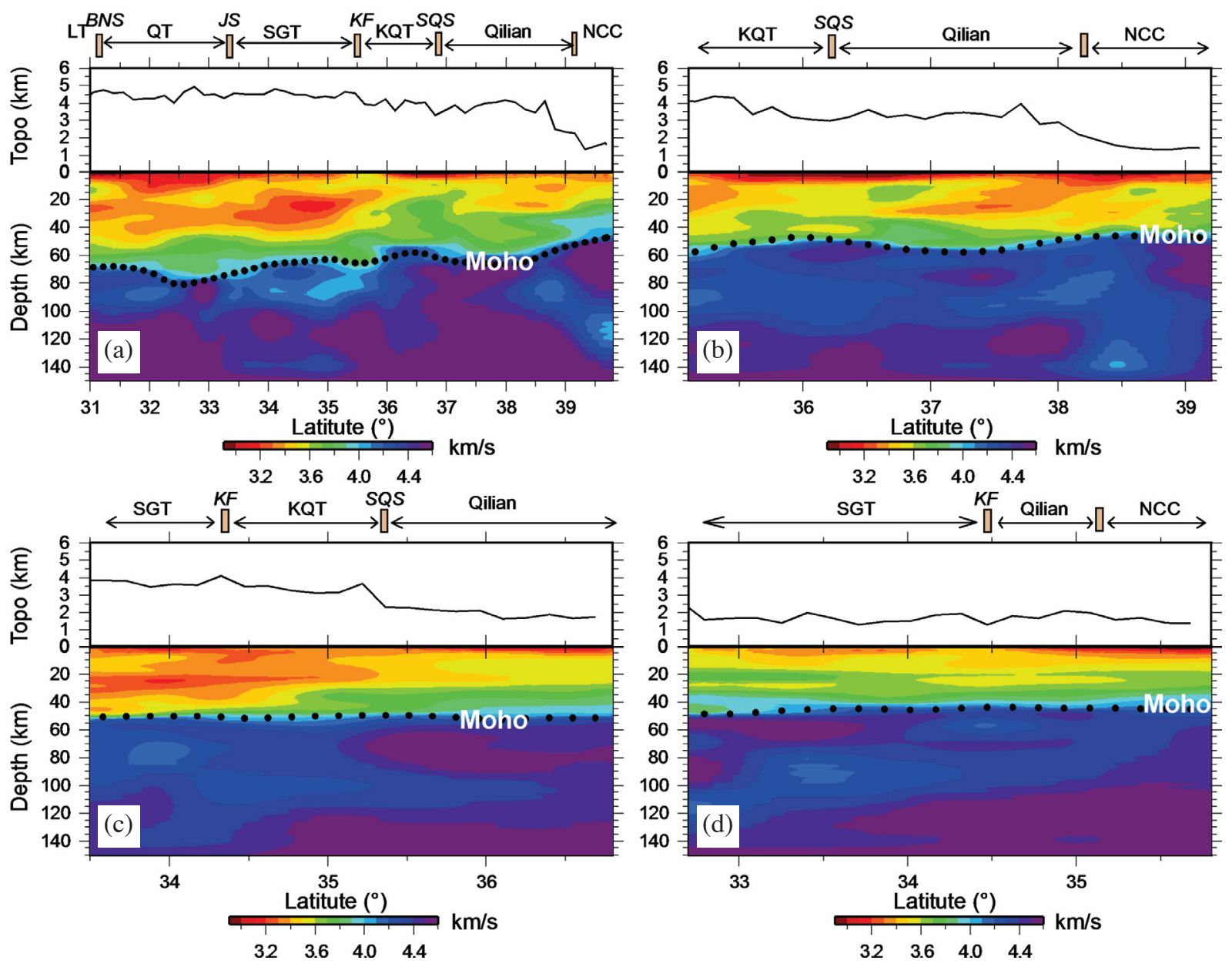

Fig. 7. The topography and velocity structure beneath the four profiles as marked in Fig. 6. The tectonic units are the same as Fig. 1.



Fig. 8. The correlation between average Vs in the crust (from $4 \mathrm{~km}$ below sedimentary layer to Moho) and uppermost mantle (the top $20 \mathrm{~km}$ of mantle). 
Acknowledgements Waveform data for this study are partly provided by Data Management Centre of China National Seismic Network at Institute of Geophysics' China Earthquake Administration (doi: 10.11998/SeisDmc/SN, http:// www.seisdmc.ac.cn). We also thank Incorporated Research Institutions for Seismology (IRIS) for providing the waveform data. This work was funded by National Science Foundation of China under Grant Nos. 41504069, 41611530695, 41774056, Youth Innovation Promotion Association CAS (YIPA) and Tuguangchi Award for Excellent Young Scholar (TGC201702).

\section{REFERENCES}

Bao, X., X. Song, M. Xu, L. Wang, X. Sun, N. Mi, D. Yu, and H. Li, 2013: Crust and upper mantle structure of the North China Craton and the NE Tibetan Plateau and its tectonic implications. Earth Planet. Sci. Lett., 369-370, 129-137, doi: 10.1016/j.epsl.2013.03.015. [Link]

Bao, X., X. Song, and J. Li, 2015: High-resolution lithospheric structure beneath Mainland China from ambient noise and earthquake surface-wave tomography. Earth Planet. Sci. Lett., 417, 132-141, doi: 10.1016/j. eps1.2015.02.024. [Link]

Chang, L., Z. Ding, C. Wang, and L. M. Flesch, 2017: Vertical coherence of deformation in lithosphere in the NE margin of the Tibetan plateau using GPS and shearwave splitting data. Tectonophysics, 699, 93-101, doi: 10.1016/j.tecto.2017.01.025. [Link]

Clark, M. K. and L. H. Royden, 2000: Topographic ooze: Building the eastern margin of Tibet by lower crustal flow. Geology, 28, 703-706, doi: 10.1130/0091-7613( 2000)28<703:TOBTEM>2.0.CO;2. [Link]

Data Management Centre of China National Seismic Network, 2007: Waveform data of China National Seismic Network. Institute of Geophysics, China Earthquake Administration. Available at http://www.seisdmc.ac.cn.

Deng, Y., W. Shen, T. Xu, and M. H. Ritzwoller, 2015: Crustal layering in northeastern Tibet: A case study based on joint inversion of receiver functions and surface wave dispersion. Geophys. J. Int., 203, 692-706, doi: 10.1093/gji/ggv321. [Link]

Deng, Y., J. Li, X. Song, and L. Zhu, 2018: Joint Inversion for Lithospheric Structures: Implications for the Growth and Deformation in Northeastern Tibetan Plateau. Geophys. Res. Lett., 45, 3951-3958, doi: 10.1029/2018GL077486. [Link]

Gao, R., H. Wang, A. Yin, S. Dong, Z. Kuang, A. V. Zuza, W. Li, and X. Xiong, 2013: Tectonic development of the northeastern Tibetan Plateau as constrained by high-resolution deep seismic-reflection data. Lithosphere, 5, 555-574, doi: 10.1130/L293.1. [Link]

Guo, X., R. Gao, H. Wang, W. Li, G. R. Keller, X. Xu,
H. Li, and J. Encarnacion, 2015: Crustal architecture beneath the Tibet-Ordos transition zone, NE Tibet, and the implications for plateau expansion. Geophys. Res. Lett., 42, 10631-10639, doi: 10.1002/2015GL066668. [Link]

Jiang, C., Y. Yang, and Y. Zheng, 2014: Penetration of mid-crustal low velocity zone across the Kunlun Fault in the NE Tibetan Plateau revealed by ambient noise tomography. Earth Planet. Sci. Lett., 406, 81-92, doi: 10.1016/j.epsl.2014.08.040. [Link]

Julià, J., C. J. Ammon, R. B. Herrmann, and A. M. Correig, 2000: Joint inversion of receiver function and surface wave dispersion observations. Geophys. J.Int., 143, 99-112, doi: 10.1046/j.1365-246x.2000.00217.x. [Link]

Kind, R., X. Yuan, J. Saul, D. Nelson, S. V. Sobolev, J. Mechie, W. Zhao, G. Kosarev, J. Ni, U. Achauer, and M. Jiang, 2002: Seismic images of crust and upper mantle beneath Tibet: Evidence for Eurasian plate subduction. Science, 298, 1219-1221, doi: 10.1126/science.1078115. [Link]

León Soto, G., E. Sandvol, J. F. Ni, L. Flesch, T. M. Hearn, F. Tilmann, J. Chen, and L. D. Brown, 2012: Significant and vertically coherent seismic anisotropy beneath eastern Tibet. J. Geophys. Res., 117, B05308, doi: 10.1029/2011JB008919. [Link]

Le Pape, F., A. G. Jones, J. Vozar, and W. Wenbo, 2012: Penetration of crustal melt beyond the Kunlun Fault into northern Tibet. Nat. Geosci., 5, 330-335, doi: 10.1038/ngeo1449. [Link]

Li, H., Y. Shen, Z. Huang, X. Li, M. Gong, D. Shi, E. Sandvol, and A. Li, 2014: The distribution of the mid-tolower crustal low-velocity zone beneath the northeastern Tibetan Plateau revealed from ambient noise tomography. J. Geophys. Res., 119, 1954-1970, doi: 10.1002/2013JB010374. [Link]

Li, J., X. Song, L. Zhu, and Y. Deng, 2017a: Joint inversion of surface wave dispersions and receiver functions with P velocity constraints: Application to southeastern Tibet. J. Geophys. Res., 122, 7291-7310, doi: 10.1002/2017JB014135. [Link]

Li, Y., X. Wang, R. Zhang, Q. Wu, and Z. Ding, 2017b: Crustal structure across the NE Tibetan Plateau and Ordos Block from the joint inversion of receiver functions and Rayleigh-wave dispersions. Tectonophysics, 705, 33-41, doi: 10.1016/j.tecto.2017.03.020. [Link]

Liang, X., E. Sandvol, Y. J. Chen, T. Hearn, J. Ni, S. Klemperer, Y. Shen, and F. Tilmann, 2012: A complex Tibetan upper mantle: A fragmented Indian slab and no south-verging subduction of Eurasian lithosphere. Earth Planet. Sci.Lett., 333-334, 101-111, doi: 10.1016/j.epsl.2012.03.036. [Link]

Ligorría, J. P. and C. J. Ammon, 1999: Iterative deconvolution and receiver-function estimation. Bull. Seismol. 
Soc. Am., 89, 1395-1400.

Liu, Q. Y., R. D. van der Hilst, Y. Li, H. J. Yao, J. H. Chen, B. Guo, S. H. Qi, J. Wang, H. Huang, and S. C. Li, 2014: Eastward expansion of the Tibetan Plateau by crustal flow and strain partitioning across faults. Nat. Geosci., 7, 361-365, doi: 10.1038/ngeo2130. [Link]

Meyer, B., P. Tapponnier, L. Bourjot, F. Métivier, Y. Gaudemer, G. Peltzer, S. Guo, and Z. Chen, 1998: Crustal thickening in Gansu-Qinghai, lithospheric mantle subduction, and oblique, strike-slip controlled growth of the Tibet plateau. Geophys. J. Int., 135, 1-47, doi: 10.1046/j.1365-246X.1998.00567.x. [Link]

Neil, E. A. and G. A. Houseman, 1997: Geodynamics of the Tarim Basin and the Tian Shan in central Asia. Tectonics, 16, 571-584, doi: 10.1029/97TC01413. [Link]

Pandey, S., X. Yuan, E. Debayle, F. Tilmann, K. Priestley, and X. Li, 2015: Depth-variant azimuthal anisotropy in Tibet revealed by surface wave tomography. Geophys. Res.Lett.,42,4326-4334, doi: 10.1002/2015GL063921. [Link]

Royden, L. H., B. C. Burchfiel, R. W. King, E. Wang, Z. Chen, F. Shen, and Y. Liu, 1997: Surface deformation and lower crustal flow in eastern Tibet. Science, 276, 788-790, doi: 10.1126/science.276.5313.788. [Link]

Sambridge, M., 1999: Geophysical inversion with a neighbourhood algorithm - I. Searching a parameter space. Geophys. J. Int., 138, 479-494, doi: 10.1046/j.1365246X.1999.00876.x. [Link]

Shen, W., M. H. Ritzwoller, V. Schulte-Pelkum, and F.-C. Lin, 2013: Joint inversion of surface wave dispersion and receiver functions: A Bayesian Monte-Carlo approach. Geophys. J. Int., 192, 807-836, doi: 10.1093/ gji/ggs050. [Link]

Shen, X., X. Yuan, and M. Liu, 2015: Is the Asian lithosphere underthrusting beneath northeastern Tibetan Plateau? Insights from seismic receiver functions. Earth Planet. Sci. Lett., 428, 172-180, doi: 10.1016/j. eps1.2015.07.041. [Link]

Shen, Y., D. Shi, X. Li, E. Sandvol, A. Li, and H. Li, 2008: Northeast Tibet Plateau Seismic Experiment. International Federation of Digital Seismograph Networks, Other/Seismic Network, doi: 10.7914/SN/ZV_2008. [Link]

Tapponnier, P., Z. Xu, F. Roger, B. Meyer, N. Arnaud, G. Wittlinger, and J. Yang, 2001: Oblique stepwise rise and growth of the Tibet Plateau. Science, 294, 16711677, doi: 10.1126/science.105978. [Link]

Tian, X., Z. Liu, S. Si, and Z.Zhang, 2014: The crustal thickness of NE Tibet and its implication for crustal shortening. Tectonophysics, 634, 198-207, doi: 10.1016/j. tecto.2014.07.001. [Link]

Vergne, J., G. Wittlinger, Q. Hui, P. Tapponnier, G. Poupinet, J. Mei, G. Herquel, and A. Paul, 2002: Seismic evidence for stepwise thickening of the crust across the
NE Tibetan plateau. Earth Planet. Sci. Lett., 203, 2533, doi: 10.1016/S0012-821X(02)00853-1. [Link]

Wang, C.-Y., L. M. Flesch, P. G. Silver, L.-J. Chang, and W. W. Chan, 2008: Evidence for mechanically coupled lithosphere in central Asia and resulting implications. Geology, 36, 363-366, doi: 10.1130/G24450A.1. [Link]

Wang, Q., F. Niu, Y. Gao, and Y. Chen, 2016: Crustal structure and deformation beneath the NE margin of the Tibetan plateau constrained by teleseismic receiver function data. Geophys. J. Int., 204, 167-179, doi: 10.1093/ gji/ggv420. [Link]

Wei, X., M. Jiang, X. Liang, L. Chen, and Y. Ai, 2017: Limited southward underthrusting of the Asian lithosphere and material extrusion beneath the northeastern margin of Tibet, inferred from teleseismic Rayleigh wave tomography. J. Geophys. Res., 122, 7172-7189, doi: 10.1002/2016JB013832. [Link]

Wu, C., T. Xu, J. Badal, Z. Wu, and J. Teng, 2015: Seismic anisotropy across the Kunlun fault and their implications for northward transforming lithospheric deformation in northeastern Tibet. Tectonophysics, 659, 91101, doi: 10.1016/j.tecto.2015.07.030. [Link]

Xu, T., Z. Wu, Z. Zhang, X. Tian, Y. Deng, C. Wu, and J. Teng, 2014: Crustal structure across the Kunlun fault from passive source seismic profiling in East Tibet. Tectonophysics, 627, 98-107, doi: 10.1016/j. tecto.2013.11.010. [Link]

Xu, X., F. Niu, Z. Ding, and Q. Chen, 2018: Complicated crustal deformation beneath the NE margin of the Tibetan plateau and its adjacent areas revealed by multistation receiver-function gathering. Earth Planet. Sci. Lett., 497, 204-216, doi: 10.1016/j.eps1.2018.06.010. [Link]

Xu, Z. J., X. Song, and L. Zhu, 2013: Crustal and uppermost mantle $\mathrm{S}$ velocity structure under Hi-CLIMB seismic array in central Tibetan Plateau from joint inversion of surface wave dispersion and receiver function data. Tectonophysics, 584, 209-220, doi: 10.1016/j.tecto.2012.08.024. [Link]

Ye, Z., R. Gao, Q. Li, H. Zhang, X. Shen, X. Liu, and C. Gong, 2015: Seismic evidence for the North China plate underthrusting beneath northeastern Tibet and its implications for plateau growth. Earth Planet. Sci. Lett., 426, 109-117, doi: 10.1016/j.eps1.2015.06.024. [Link]

Yeck, W. L., A. F. Sheehan, and V. Schulte-Pelkum, 2013: Sequential $H-\varkappa$ stacking to obtain accurate crustal thicknesses beneath sedimentary basins. Bull. Seismol. Soc. Am., 103, 2142-2150, doi: 10.1785/0120120290. [Link]

Yin, A., Y.-Q. Dang, M. Zhang, X.-H. Chen, and M. W. McRivette, 2008: Cenozoic tectonic evolution of the Qaidam basin and its surrounding regions (Part 3): 
Structural geology, sedimentation, and regional tectonic reconstruction. Geol. Soc. Am. Bull., 120, 847876, doi: 10.1130/B26232.1. [Link]

Zhang, P.-Z., Z. Shen, M. Wang, W. Gan, R. Bürgmann, P. Molnar, Q. Wang, Z. Niu, J. Sun, J. Wu, S. Hanrong, and Y. Xinzhao, 2004: Continuous deformation of the Tibetan Plateau from global positioning system data. Geology, 32, 809-812, doi: 10.1130/G20554.1. [Link]

Zhang, Z., S. Klemperer, Z. Bai, Y. Chen, and J. Teng, 2011: Crustal structure of the Paleozoic Kunlun orogeny from an active-source seismic profile between Moba and Guide in East Tibet, China. Gondwana Res., 19, 994-1007, doi: 10.1016/j.gr.2010.09.008. [Link]

Zhang, Z., Z. Bai, S. L. Klemperer, X. Tian, T. Xu, Y.Chen, and J. Teng, 2013: Crustal structure across northeastern Tibet from wide-angle seismic profiling: Constraints on the Caledonian Qilian orogeny and its reactivation. Tectonophysics, 606, 140-159, doi: 10.1016/j. tecto.2013.02.040. [Link]

Zhao, J., X. Yuan, H. Liu, P. Kumar, S. Pei, R. Kind, Z. Zhang, J. Teng, L. Ding, X. Gao, Q. Xu, and W. Wang, 2010: The boundary between the Indian and Asian tectonic plates below Tibet. Proc. Natl. Acad. Sci., 107, 11229-11233, doi: 10.1073/pnas.1001921107. [Link]
Zhao, W., P. Kumar, J. Mechie, R. Kind, R. Meissner, Z. Wu, D. Shi, H. Su, G. Xue, M. Karplus, and F. Tilmann, 2011: Tibetan plate overriding the Asian plate in central and northern Tibet. Nat. Geosci., 4, 870-873, doi: 10.1038/NGEO1309. [Link]

Zheng, D., H. Li, Y. Shen, J. Tan, L. Ouyang, and X. Li, 2016: Crustal and upper mantle structure beneath the northeastern Tibetan Plateau from joint analysis of receiver functions and Rayleigh wave dispersions. Geophys. J. Int., 204, 583-590, doi: 10.1093/gji/ggv469. [Link]

Zheng, X.-F., Z.-X. Yao, J.-H. Liang, and J. Zheng, 2010: The role played and opportunities provided by IGP DMC of China National Seismic Network in Wenchuan earthquake disaster relief and researches. Bull.Seismol. Soc. Am., 100, 2866-2872, doi: 10.1785/0120090257. [Link]

Zhu, L. and D. V. Helmberger, 1998: Moho offset across the northern margin of the Tibetan Plateau. Science, 281, 1170-1172, doi: 10.1126/science.281.5380.1170. [Link]

Zhu, L. and H. Kanamori, 2000: Moho depth variation in southern California from teleseismic receiver functions. J. Geophys. Res., 105, 2969-2980, doi: 10.1029/1999JB900322. [Link] 